\title{
ADITIVOS COMO CONSERVANTES QUÍMICOS
}

\author{
Daniella Vincenzi ${ }^{1}$ \\ Leticia de Jesus Mendes ${ }^{2}$ \\ Vinícius Medeiros Mota ${ }^{3}$
}

RESUMO: O artigo elaborado apresentará uma história, e funcionalidade, dos meios de conservação de alimentos que continuam sendo utilizados atualmente, tendo como temática principal os conservantes químicos utilizados nas indústrias alimentícias, a ação que pode fornecer ao alimento, complementando com os malefícios causados à saúde humana e substâncias pelas quais podem ser substituídas. Com o método utilizado sendo o exploratório, através de artigos científicos, revistas, periódicos e legislações. Neste trabalho verificou-se que apesar de possuir uma série de legislações fornecidas pelos órgãos controladores, ainda existem problemas e reclamações de consumidores devido a reações adversas causadas por alguns conservantes. Pode-se ainda afirmar que os conservantes que acarretam reações mais graves, vem sendo substituídos por outras substâncias que tenham o mesmo tipo de ação para a conservação do alimento.

Palavras-chave: Conservantes. Alimentos. Malefícios. Saúde.

ABSTRACT: The elaborated article will present a history, and functionality, of the means of food preservation that continue to be used today, having as its main theme the chemical preservatives used in the food industries, the action it can provide to food, complementing the harm caused to human health and substances with which they can be substituted. With the method used being the exploratory, through scientific articles, magazines, periodicals and legislation. In this work it was found that despite having a series of legislation provided by Organs controlling bodies, there are still problems and complaints from consumers due to adverse reactions caused by some preservatives. It can also be said that preservatives that cause more severe reactions have been replaced by other substances that have the same type of action for food preservation.

Keywords: Preservatives. Foods. Harm. Health.

\section{INTRODUÇÃO}

Há uma grande perda de alimentos devido à uma má conservação. É muito comum que ocorra a degradação da comida durante o transporte e armazenamento, isto ocorre em

\footnotetext{
IFormação Acadêmica: Química Bacharelado. Instituição: Faculdades Oswaldo Cruz ${ }^{2}$ Formação Acadêmica: Química Bacharelado Instituição: Faculdades Oswaldo Cruz ${ }^{3}$ Formação Acadêmica: Química Bacharelado. Instituição: Faculdades Oswaldo Cruz
} 
razão da reprodução de micro-organismos que se multiplicam gerando uma alteração física e química tornando seu consumo prejudicial.

Existem diversos métodos utilizados com a finalidade de conservar os alimentos, como: pasteurização, congelamento, resfriamento, liofilização entre outros. Com o passar dos anos

novas técnicas foram desenvolvidas e aperfeiçoadas a fim de solucionar a questão de conservação de alimentos (MODANEZ, 2012).

Uma prática muito utilizada na conservação dos alimentos é o uso de conservantes, que tem como finalidade a prevenção e/ou inibição de micro-organismos prejudiciais, evitando alterações químicas indesejadas, mantendo a qualidade do alimento, além de prolongar o tempo de prateleira do alimento. Sua utilização é muito comum para conservar características como sabor, cheiro, aparência, consistência, e seu valor nutritivo (ADITIVOS INGREDIENTES № ${ }_{123}, 2015$ ).

Em países tropicais o uso de conservantes possui maior relevância, pois esse tipo de clima é úmido e as temperaturas são mais propicias ao desenvolvimento microbiano. Seu uso também é essencial quando as instalações de armazenamento e o transporte são inadequados, ou quando o percurso entre o centro produtivo e o consumidor final é muito extenso (FOOD INGREDIENTS BRASIL №눙, 20II).

É importante constatar que há muitos tipos de conservantes e que cada um será utilizado em produtos específicos dependendo de sua composição, variação de $\mathrm{pH}$ e temperatura (ADITIVOS INGREDIENTES $\mathrm{N}^{\circ}{ }^{123}$, 2015). $\mathrm{O}$ uso dessas substâncias possui uma recomendação de quantidade máxima permitida em cada tipo de alimento, para que ocorra o efeito desejado e não ultrapasse os valores indicados de ingestão (AUN et al., 201I).

Entretanto, o uso dessa técnica de conservação vem apresentando incertezas relacionadas à segurança ao consumir essas substâncias, referentes a possíveis complicações e malefícios que podem trazer ao ser humano. O estudo realizado resulta em pesquisas, através da literatura científica, para contestar as questões relacionadas aos meios 
de conservação e, principalmente, aos conservantes químicos, a fim de demonstrar os impactos à saúde humana.

\section{BREVE HISTÓRICO}

$\mathrm{Na}$ era paleolítica, os homens caçavam e seu alimento e o consumiam imediatamente, por isso sempre comiam alimentos crus quando eram provenientes de caça, além disso consumiam frutos, raízes e insetos. Muitas vezes não havia disponibilidade de caça, e por isso se fez necessário criar meios para que o alimento durasse por maior tempo.

Inicialmente era utilizada a parte mais fria e escura da caverna para estocar alimentos. Temperaturas mais baixas inibem e retardam reações químicas que deterioram os alimentos e a ação enzimática nos componentes do alimento, o que diminui a atividade dos micro-organismos (DIONYSIO; MEIRELLES, 2009).

O homem primitivo usava o sol para secar os alimentos, pois percebeu que ao fazer isso a carne durava mais tempo sem estragar. O processo de secagem retira a água e diminui a ação dos microrganismos presentes.

Após a descoberta do fogo foi criado o método de defumação. O homem préhistórico também aprendeu que o uso de sal nas carnes auxiliava em sua conservação, e o uso de condimentos e a realização de fermentação de produtos de origem animal e vegetal (DIONYSIO; MEIRELLES, 2009).

A fermentação era uma técnica muito utilizada pelos índios, que fazia bebidas alcoólicas através da fermentação da mandioca, e essa técnica usada por eles é muito utilizada na fabricação de outras bebidas (DIONYSIO; MEIRELLES, 2009).

No tempo das grandes navegações, a conservação de alimentos se fez mais necessária, pois a tripulação fazia longas viagens, necessitando de alimentos por todo esse período. Como o alimento não era bem armazenado e conservado muitos tripulantes vinham a óbito (DIONYSIO; MEIRELLES, 2009).

Muito tempo depois, Louis Pasteur realizou um experimento que demonstrava a ação do calor nos micro-organismos, o que trazia maior durabilidade às bebidas. A técnica 
é conhecida como Pasteurização em homenagem a ele, e é utilizada até hoje (DIONYSIO; MEIRELLES, 2009).

\section{TIPOS DE CONSERVAÇÃO}

Como visto, desde a pré-história a conservação dos alimentos era, e continuam sendo, algo de extrema importância. Os métodos de conservação normalmente são divididos em grupos onde ocorre uma alteração principal com o alimento, sendo: temperaturas baixas ou elevadas, controle de umidade, radiação e aditivos químicos como os principais e mais utilizados atualmente.

Dentre os meios de conservação que utilizam a temperatura como principal alteração temos branqueamento, pasteurização, esterilização, resfriamento e congelamento. Nos métodos onde o controle de umidade é a principal modificação temos secagem natural, secagem artificial e liofilização.

\section{CONSERVANTES QUÍMICOS}

A conservação por aditivos químicos é definida como a adição de substâncias químicas nos alimentos, com o objetivo de melhorar o tempo de prateleira, o sabor, aspecto e consistência. Para este método, há uma classificação específica em relação aos aditivos, que serão utilizados com o respectivo alimento, na forma correta e necessária. Dentre os principais, nesta classificação de aditivos, estão: os antioxidantes, acidulantes, umectantes, estabilizantes, aromatizantes, edulcorante e conservantes (TECNOLOGIA DE ALIMENTO, 2013).

Segundo a Food and Agriculture Organization of the United Nations (FAO), em contexto mundial, cerca de $30 \%$ dos alimentos produzidos são perdidos anualmente por conta de sua degradação. Desta forma, o uso de aditivos químicos, como os conservantes, vem sendo cada vez mais utilizado devido à uma grande eficácia com as aplicações feitas nos alimentos, e assim, torna-se necessário o acompanhamento de órgãos controladores no uso dessas substâncias, para que não cause nenhum risco à saúde humana (COPETTI, 2019). 
A portaria no 540 - SVS/MS de 27 de outubro de 1997 publicada pela Agência Nacional de Vigilância Sanitária (ANVISA) estabeleceu, aditivos químicos, como:

\begin{abstract}
Qualquer ingrediente adicionado intencionalmente aos alimentos, sem propósito de nutrir, com o objetivo de modificar as características físicas, químicas, biológicas ou sensoriais, durante a fabricação, processamento, preparação, tratamento, embalagem, acondicionamento, armazenagem, transporte ou manipulação de um alimento. Ao agregar-se poderá resultar em que o próprio aditivo ou seus derivados se convertam em um componente de tal alimento. Esta definição não inclui os contaminantes ou substâncias nutritivas que sejam incorporadas ao alimento para manter ou melhorar suas propriedades nutricionais (ANVISA, 1997).”
\end{abstract}

Esta fiscalização feita pela ANVISA, têm como objetivo, além de preservar a saúde, fornecer a autorização para o uso em indústrias alimentícias. Deve-se declarar de forma clara quais os limites máximos utilizados, sem que ultrapasse a Ingestão Diária Aceitável (IDA); a respectiva função para o alimento; e a categoria de alimento permitida (ANVISA, 2009).

O uso de aditivos e conservantes se torna algo primordial no caso de armazenamento dos alimentos, dependendo das condições de temperaturas ou de algum excesso de água, pode ocasionar a proliferação de fungos, bactérias e leveduras. Com o uso dessas substâncias químicas, evita-se este crescimento dos micro-organismos, mantendo também a qualidade, consistência, valor nutricional e controle do $\mathrm{pH}$ apropriado do alimento (RODRIGUES et al, 2013).

Para que seja concedido o uso desta técnica de aplicação de conservantes, deve-se passar por uma série de pesquisas afim de verificar a toxicidade da substância e os riscos que podem causar a saúde humana decorrente de seu uso frequente. Estas análises são feitas periodicamente, mesmo depois de ser aprovado, mantendo o conservante em observação para que ser revisado sempre que for preciso (RODRIGUES et al, 2013).

De acordo com a Food Ingredients Brasil (20II), os conservantes mais utilizados nos alimentos são nisina e natamicina; ácido acético e acetatos; ácido láctico e derivados; nitritos e nitratos; ácido sórbico e derivados; ácido benzóico e os sais; ácido propiônico e os sais; ácidos p-hidroxibenzóico e seus ésteres (parabenos); e dióxido de enxofre com seus derivados. 
Conforme a resolução no $04 / 88$ do Ministério da Saúde (BRASIL, 1988), os conservantes utilizados, com permissão, no Brasil são apresentados na Tabela I. Também é descrito as principais aplicações do respectivo conservante, acompanhado do seu número de INS (Sistema Internacional de Numeração de Aditivos Alimentares) - método elaborado pelo Comitê do Codex Alimentarius para auxiliar na identificação dos aditivos nas listas de

ingredientes, e assim possibilitando ao usuário um meio mais usual quando precisar consultar algum aditivo ou conservante em específico (ANVISA, 20I0).

Tabela I Relação dos conservantes permitidos, principais aplicações e número de INS

\section{Conservantes}

Ácido sórbico e seus sais

(sódio, cálcio e potássio)
Número de INS

200 a 203

\section{Principais aplicações}

Queijos, laticínios, carnes, produtos a base de peixe, pão e produtos de confeitaria
280 a 283
sais (sódio, cálcio e potássio)
Ácido propiônico e seus
Produtos de panificação: margarinas, farinhas e doces

210 a 213

(sódio, cálcio e potássio)
Geléias, doces, margarinas, molhos e bebidas carbonatadas (com gás)

Margarinas, fermento em pó e maioneses

$\begin{array}{ll}\text { Ácido acético e acetatos } & 260 \text { a } 263\end{array}$

Legumes em conserva,

(sódio, cálcio e potássio)

Tabela I Relação dos conservantes permitidos, principais aplicações e número de INS 


\section{Conservantes}

Ácidos p-hidroxibenzóico e

seus ésteres (parabenos)
Número de INS

214 a 219

\section{Principais aplicações}

Adoçantes, bebidas

fermentadas e não

carbonatadas (sem gás)

\begin{tabular}{ccc} 
Nitritos e nitratos & 249 a 252 & Alimentos embutidos \\
\hline $\begin{array}{c}\text { Nisina e natamicina } \\
\text { Dióxido de enxofre e } \\
\text { derivados }\end{array}$ & 234 e 235 a 228 & Queijos processados \\
\hline
\end{tabular}

Fonte: BRASIL, 1988

A função dos conservantes químicos quando colocados nos alimentos, é impedir ou retardar as mudanças provocadas através dos micro-organismos. Deve-se considerar que a eficácia de cada conservantes pode variar caso utilize outros tipos de inibidores da proliferação dos micro-organismos, como o sal, açúcar, vinagre, teor de água no alimento, $\mathrm{pH}, \mathrm{e}$ até mesmo o nível de contaminação do alimento (ADITIVOS \& INGREDIENTES, 2009).

Existem alguns tipos de micro-organismos, e eles podem ser separados em três principais grupos: micro-organismos deterioradores, aqueles que geram alterações sensoriais afetando a qualidade do alimento, como sabor, textura, odor e aparência; microorganismos patogênicos, aqueles que proporcionam o desenvolvimento de infecções e intoxicações nas pessoas que consumirem tal alimento que esteja contaminado; e microorganismos usados na produção de alimentos fermentados, aqueles que geram reações químicas características para que ocorra a alteração sensorial desejada para o alimento, sendo muito utilizado em vinhos, queijos e pães (FOOD INGREDIENTS BRASIL, 20II)

Portanto, para definir qual conservantes deve ser utilizado, tem-se que considerar alguns fatores, como o efeito que pode gerar no paladar; custo e eficiência; facilidade em que é aplicado; e os tipos de micro-organismos que deseja controlar (ADITIVOS \& 
INGREDIENTES, 2009). Cada conservante é específico para cada tipo de alimento, devendo sempre seguir as legislações a respeito do seu uso e quantidade máxima permitida para ingestão, com o propósito de evitar problemas de saúde à população.

Os principais conservantes abordados no presente trabalho estão descritos na tabela

2, juntamente com sua fórmula estrutural.

Tabela 2 Principais conservantes e suas fórmulas estruturais.

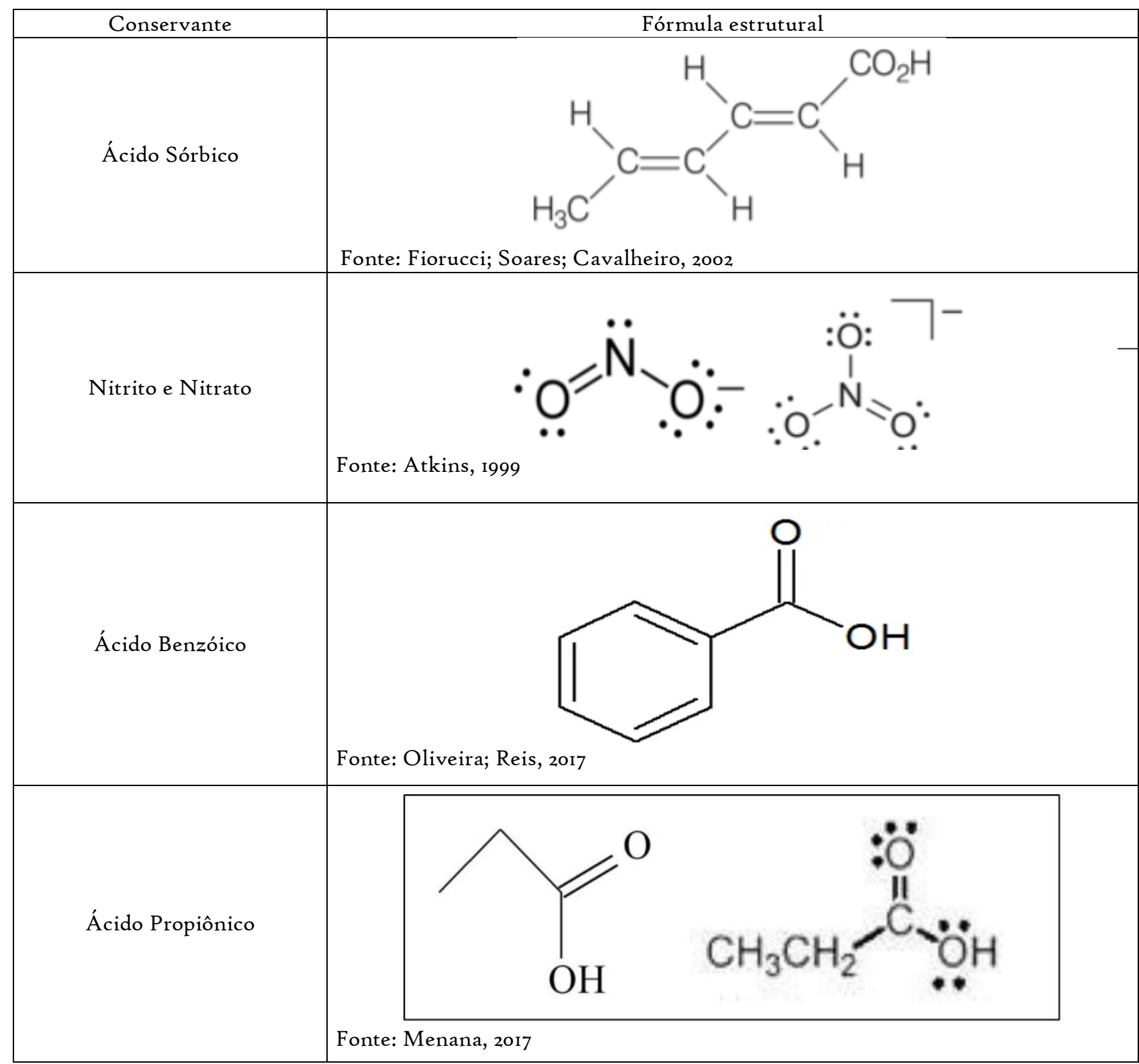




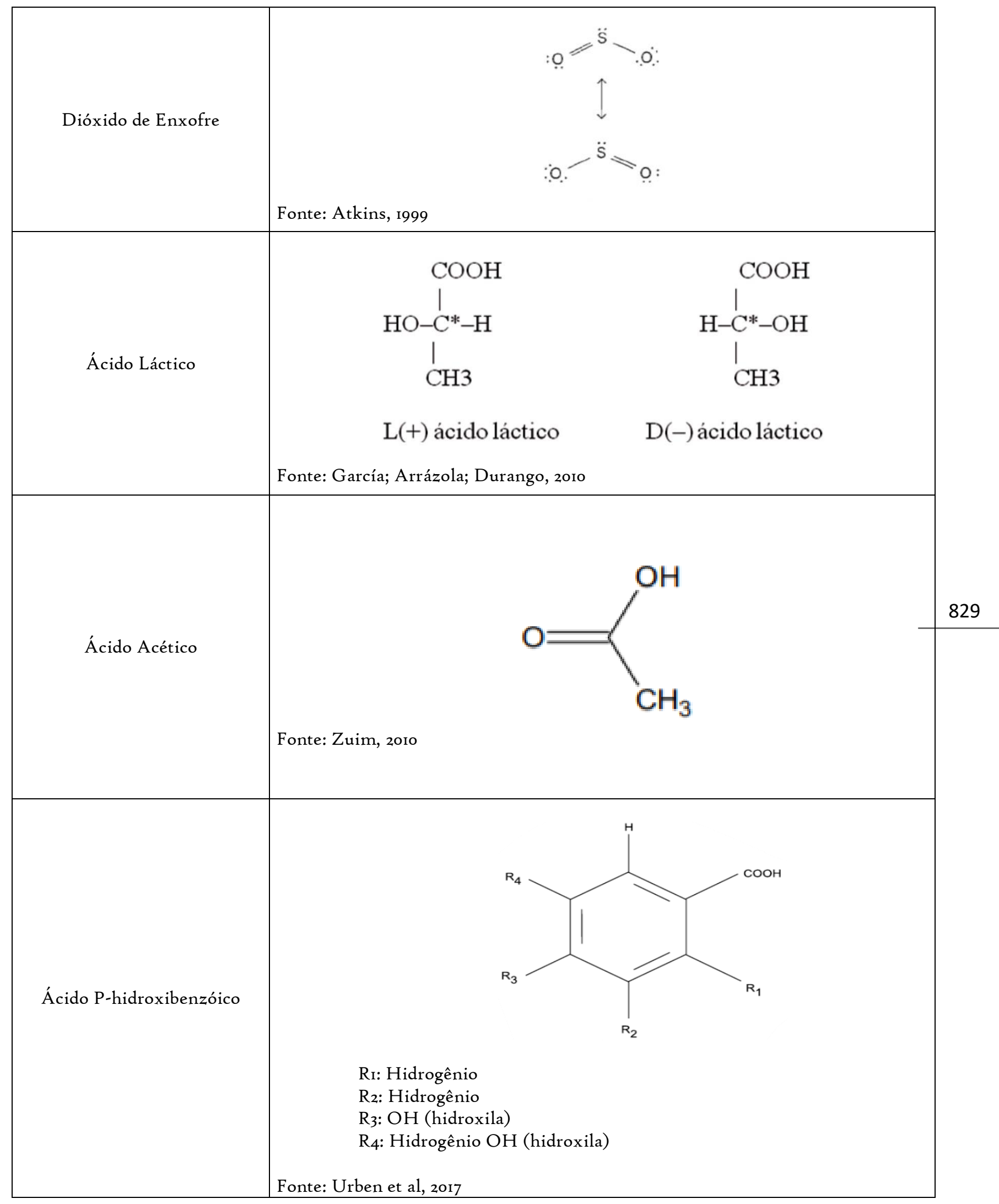




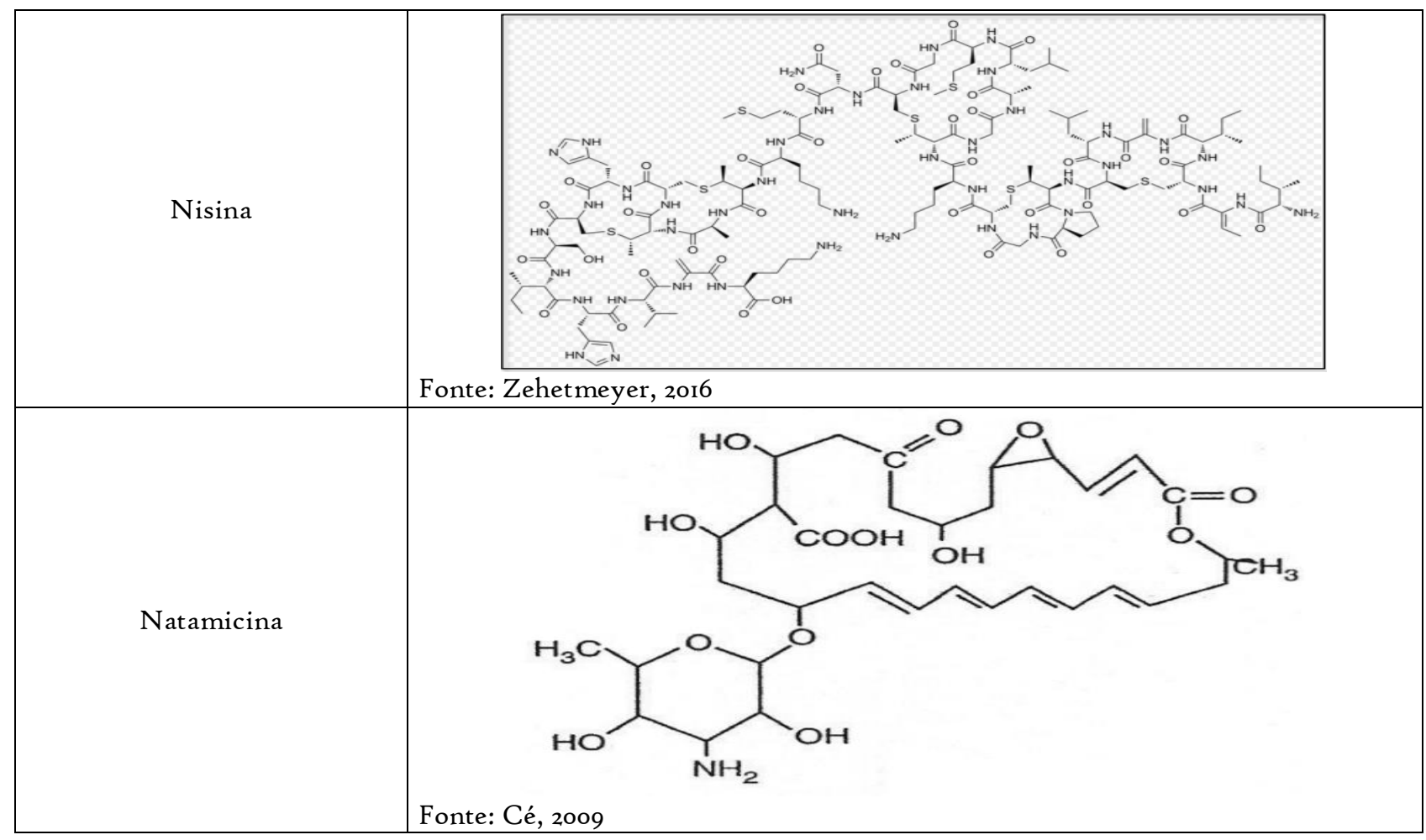

\section{I. ÁCIDO SÓRBICO E SEUS SAIS}

O Ácido Sórbico é apresentado na forma de pó ou cristais levemente esbranquiçados, sua fórmula molecular é $\mathrm{C}_{6} \mathrm{H}_{8} \mathrm{O}_{2}$. É um ácido orgânico, pouco solúvel em água e com uma estrutura molecular de cadeia aberta e insaturada podendo ter suas variações de sorbatos, como: de sódio, cálcio e potássio.

Em 1940 foi descoberta a sua capacidade de conservação antimicrobiana, e posteriormente, a liberação para uso em alimentos sendo considerados seguros e inofensivos. $\mathrm{O}$ ácido sórbico é eficaz contra leveduras e bolores funcionando também para algumas bactérias, já os seus sais, sorbatos, são eficazes dependendo dos tipos microbianos, espécies, cepas e fatores ambientais (RODRIGUES et al, 2013). Atualmente, o sorbato de potássio, por exemplo, é bastante utilizado nos produtos cárneos como inibidor da bactéria Clostridium botulinum que é responsável pela doença do botulismo, substituindo assim o uso de nitritos e nitratos (DAVIDSON; SOFOS; BRANEN, 2005).

Devido a várias pesquisas científicas, foi estipulado um valor de IDA em $25 \mathrm{mg} / \mathrm{kg}$ de peso corporal, essa grande quantidade estabelecida é justificada pelo fato de esta 
substância demonstrar raramente alergias e reações adversas (ADITIVOS \& INGREDIENTES, ANO).

Este tipo de conservante possui ótimos resultados na conservação de produtos cosméticos e medicamentos, porém seu foco é maior no ramo alimentício, ocorrendo uma grande aplicação em produtos laticínios, carnes, queijos e produtos de panificação. Os métodos utilizados para o uso desse conservante podem ser por meio de adição direta no alimento, pulverização, sova, imersão ou até mesmo incorporação na embalagem (ADITIVOS \& INGREDIENTES, ANO).

\subsection{NITRITOS E NITRATOS}

Nitritos e nitratos são substâncias que se mostram em coloração branca ou amarelada e que possuem uma grande afinidade com a água, recebendo a característica de ser higroscópica. Sua fórmula molecular é, respectivamente, $\mathrm{NO}_{2}-$ e $\mathrm{NO}_{3}$ e pode ser encontrado sob forma de pó, cristais ou barras (RODRIGUES et al, 2013).

A estrutura molecular tanto do nitrito, quanto do nitrato, mantém um íon de carga negativa para que um íon de carga positiva se junte formando seus sais. Somente quatro tipos de sais de nitritos e nitratos é permitido utilizar nos alimentos, sendo eles: nitrito de potássio, nitrito de sódio, nitrato de potássio e nitrato de sódio (RODRIGUES et al, 2013).

Estes conservantes possuem ação antimicrobiana diretamente contra bactérias, sendo muito usado nos produtos curados para ajudar na inibição da Clostridium botulinum, microorganismo responsável pela doença do botulismo (AZEREDO, 2012). Porém, devido à alguns malefícios que essas substâncias acarretam ao humano, os nitritos e nitratos, para esta bactéria em específico, estão sendo substituídos pelo sorbato de potássio, como dito anteriormente (DAVIDSON; SOFOS; BRANEN, 2005).

Segundo a Food Ingredientes Brasil (20II), a aplicação de nitritos e nitratos nos produtos cárneos, proporciona alterações sensoriais que agrade o consumidor, como: a cor, o sabor e sua textura. O conservante reage com a mioglobina, pigmento presente na carne, formando assim a cor característica de carne curada, chamada nitromioglobina, garantindo o tom avermelhado de carne por um longo período. 
Devido à alta preocupação com estes conservantes em relação a saúde humana, a ANVISA mantém um controle rígido estabelecendo valores máximos de cada substância para uma certa quantia de produto, sendo o limite máximo de nitrito de sódio e nitrito de potássio o,or5g/roog de produto; e limite máximo de nitrato de sódio e nitrato de potássio de $0,0309 /$ Ioog de produto (BRASIL, I999).

\section{3. ÁCIDO BENZÓICO E SEUS SAIS}

Segundo Pérez (2016), este conservante é encontrado naturalmente em plantas proporcionando funções importantes no metabolismo. Possui como fórmula molecular $\mathrm{C}_{7} \mathrm{H}_{6} \mathrm{O}_{2}$, sua estrutura molecular é caracterizada por ácido carboxílico aromático sendo apresentado sob forma de cristais incolores com solubilidade em clorofórmio, etanol, metanol, acetona e benzeno (OLIVEIRA; REIS, 2017).

Foi um dos primeiros conservantes liberado para uso em alimentos e, consequentemente, os seus sais, se tornaram um dos mais usados atualmente devido à um baixo custo de produção, facilidade para incorporar nos alimentos e uma baixa taxa de toxicidade (CHIPLEY apud ARIAS, 2019).

A efetividade destes conservantes varia de acordo com o $\mathrm{pH}$, sendo utilizado em sua maioria nos alimentos de baixo $\mathrm{pH}$. Quanto maior a acidez de um alimento, menor será a concentração de ácido benzóico para a conservação, podendo ser usado com combinações de outros conservantes como sorbatos e dióxido de enxofre (ARIAS, 2019).

Possui ação antibacteriana e antifúngicas, sendo um bom conservante para inibição da proliferação de bactérias, fungos e leveduras (COSTA, 2015). Devido à inúmeros estudos foi comprovado um baixo nível de toxicidade, gerando assim um controle da ANVISA para que mantenha o valor de IDA para os benzoatos, seja de sódio, cálcio ou potássio, entre 0,3 e o,9mg/kg de peso corpóreo (MACHADO et al, 2007).

Por fornecer um sabor característico, forte e apimentado, resulta como um aspecto negativo ao consumidor. Portanto, o uso desta substância é limitado para uma certa quantidade de alimentos, sendo um dos maiores as bebidas gaseificadas, tal como margarinas, geléias, molhos e doces (FOOD INGREDIENTS BRASIL, 20II). 


\section{4. ÁCIDO PROPIÔNICO E SEUS SAIS}

O ácido propiônico tem por característica ser um líquido incolor, oleoso e possuir um forte odor, além de ser um ácido orgânico monocarboxílico, com cadeia aberta e saturada, sua fórmula química é $\mathrm{C}_{3} \mathrm{H}_{6} \mathrm{O}_{2}$. Na nomenclatura da IUPAC é conhecido como ácido propanóico. É um composto polar, capaz de formar pontes de hidrogênio, em água e álcool é solúvel e em soluções aquosas ioniza-se parcialmente. Pode formar sais de cálcio, potássio, sódio; também o de amônia, porém seu uso como aditivos alimentares é proibido na União Europeia (EFSA, 2011; CASTRO, 2014; NGOME, 2013 apud MENANA, 2017).

Em geral é encontrado em queijos, onde é gerado de forma espontânea. Nesses alimentos tem como propriedade a limitação do crescimento de fungos. Outra maneira de encontrar o ácido propiônico de forma natural é em um dos produtos gerados na digestão da celulose pelas bactérias que habitam no rúmen dos animais herbívoros (ADITIVOS \& INGREDIENTES, 2015).

Sua ação contra as bactérias não é tão eficaz como para bolores, e para leveduras

não há efeito nenhum usando as quantidades recomendadas para os alimentos. É bastante usado na indústria de panificação pois possuem pouca atuação contra os fermentos biológicos. Para produtos salgados o tipo de propionato mais utilizado é o de cálcio, já para os produtos doce usa-se o propionato de sódio (ADITIVOS \& INGREDIENTES, 2015).

Sua dosagem máxima recomendada não foi determinada e por isso não há limites de concentrações nesse tipo de produto, sendo a única determinação para usá-lo é obedecer às Boas Práticas de Fabricação (BPF) (ADITIVOS \& INGREDIENTES, 2009).

\subsection{DIÓXIDO DE ENXOFRE}

O dióxido de enxofre tem por características ser um gás incolor e com forte odor desagradável, com fórmula química $\mathrm{SO}_{2}$ e estrutura angular. Em contato com superfícies úmidas pode se transformar em trióxido de enxofre $\left(\mathrm{SO}_{3}\right)$ e em seguida em ácido sulfúrico $\left(\mathrm{H}_{2} \mathrm{SO}_{4}\right)(\mathrm{CETESB}, 2 \mathrm{O20})$.

O dióxido de enxofre é capaz de preservar características físicas dos alimentos como odor, textura e cor. É muito utilizado nas frutas para diminuir seu escurecimento 
durante o processo de secagem e armazenamento. Ao ser absorvido no alimento, o dióxido de enxofre substitui o ar dos tecidos vegetais, enfraquece as paredes celulares e destrói as enzimas que causam o escurecimento na superfície, além disso, também torna a cor das frutas secas mais atrativas (RAHMAN \& PERERA, 1999; SAPERS, 1993; IYENGAR \& McEVILY, 1992; TAYLOR \& BUSH, 1987; YABIKU et al. 1987; BEHRE, 1986; TAYLOR \& BUSH, 1986 apud POPOLIM, 2004).

É utilizado no combate do mofo, leveduras e bactérias. É empregado na fabricação de vinhos devido a seu efeito antimicrobiano seletivo às bactérias acéticas. $\mathrm{O}$ dióxido de enxofre não pode ser usado em alimentos que são fontes de tiamina pois ele destrói esse tipo de vitamina. Seu uso é mais indicado para frutas e vegetais, mas em alguns países é usado em carnes (ATKINS, 1999).

Sua quantidade máxima permitida é limitada pois entre 200 e 500 ppm o produto desenvolverá um cheiro desagradável. A ingestão diária aceitável é de $0,7 \mathrm{mg} / \mathrm{kg}$ de peso corpóreo, esse limite pode ser ultrapassado ao se ingerir uma grande quantidade de vinho, e por isso, há um grande estudo para que sua utilização na fabricação de vinhos seja reduzida. Devido a sua alta volatilidade o dióxido de enxofre se perde facilmente na atmosfera, o que faz com que as quantidades inicialmente aplicadas não seja a mesma no produto final (FOOD INGREDIENTS BRASIL, 20II).

\section{6. ÁCIDO LÁCTICO E SEUS DERIVADOS}

O ácido láctico é incolor, inodoro, com sabor azedo e é solúvel em água, álcool e éter. É um ácido fraco e com baixa volatilidade, formado pelos grupos funcionais álcool e ácido carboxílico. Como há um carbono assimétrico no composto, existe a isomeria óptica, sendo eles o D (-) ácido láctico e o L (+) ácido láctico (RASHID, 2008).

O ácido láctico tem um grande emprego no setor alimentício, sendo usado como acidulante, flavorizante, tamponante e como agente inibidor de bactérias deteriorantes em alimentos como pães e produtos panificados, bebidas, produtos lácteos, geleias, doces, maioneses e ovos e seus processados em conjunto com outros acidulantes (LIPINSK; SINCLAIR, 1986 apud CAPELLARI, 2010). 
É um composto capaz de intensificar sabores e aromas, além de ser um inibidor microbiano eficaz. Em decorrência de sua baixa lipossolubilidade o ácido láctico se difunde lentamente através da membrana celular, sugerindo que as perturbações do PHi da célula não é sua principal forma de inibição. É capaz de produzir um efeito inibitório ao neutralizar o gradiente dos prótons de membrana (THERON; LUES, 2oII; RAY; BHUMIA, 2008 apud MOURA, 20II).

Além do ácido láctico também são usados seus sais, lactato de sódio e lactato de potássio que diminuem a proliferação de bactérias e a taxa de crescimento dos microorganismos. Os lactatos diminuem a atividade da água, contribuindo com o bloqueio do desenvolvimento bacteriano, e então aumentando o tempo de conservação do alimento. A dosagem máxima permitida é entre 0,05 e $2 \%$ de ácido láctico (ADITIVOS \& INGREDIENTES, 2009).

\section{7. ÁCIDO ACÉTICO E ACETATOS}

O ácido acético é um componente conhecido como ácido acético glacial ou ácido de vinagre, sua fórmula é $\mathrm{CH}_{3} \mathrm{CO}_{2} \mathrm{H}$. É um composto incolor, inflamável de grau 2, corrosivo e com odor desagradável, sua temperatura de fusão é de $16,6{ }^{\circ} \mathrm{C}$ e de ebulição II $8^{\circ} \mathrm{C}$. É solúvel em água, etanol, acetona entre outros, muito instável na presença de calor, para que haja uma neutralização desse composto sempre há a utilização de $\mathrm{NaOH}$ a $5 \%$ ou até mesmo $\mathrm{Na}_{2} \mathrm{CO}_{3}$ (TEVES, 200I).

De acordo com a Food Ingredients Brasil (2012), quantidade estabelecida é de o,1\% a $0,5 \%$ em um alimento, pois em alta quantidade causa intoxicação aguda. Uma das primeiras formas de conservação por esse ácido foi pelo uso de vinagre, o qual consiste em sua composição o ácido Acético, quando parte é dissolvida em água, ele possui uma ação microbiana deixando assim que os fungos mais resistentes e bactérias não possam se proliferar. É utilizado para controlar a acidez de determinado alimento com uma diluição, muito utilizado na produção de refrigerantes, queijos e geleias (FOOD INGREDIENTS BRASIL, 2017). 


\section{8. ÁCIDO P-HIDROXIBENZÓICO E SEUS ÉSTERES (PARABENOS)}

Sua fórmula molecular é $\mathrm{HOC}_{6} \mathrm{H}_{4} \mathrm{CO}_{2} \mathrm{H}$, sendo conhecido também como ácido 4 hidroxidobenzoico. Possui uma boa solubilidade quando utilizado junto a metil-parabeno e o propil-parabeno (ADITIVOS \& INGREDIENTES, 2015).

Seu limite para ser utilizado é de até o,I \%, porém este seu gosto não é tão bom quanto outros ácidos para conservação e deixou de ser um dos mais usados, costuma ter muita utilidade hoje em cosméticos e outros produtos, foi um dos primeiros ácidos a ser liberado pela Federal Drug Administration (FDA) (ADITIVOS \& INGREDIENTES, 2015).

Contudo sua função de conservação atende ao combate dos fungos, bactérias e leveduras, seu $\mathrm{pH}$ varia entre 3 e 8, porém quanto mais baixo o valor melhor sua eficiência, pode ser usado em alimentos que precisam de fermentação, como a cerveja e o vinho e bebidas não carbonatadas como café e chás (ADITIVOS \& INGREDIENTES, 2015).

\subsection{NISINA E NATAMICINA}

Seu uso muitas vezes é usado em conjunto com o ácido sórbico, no qual é mais eficaz assim para se obter um resultado melhor pode ainda ser adicionado o ácido cítrico, o EDTA e os fosfatos na produção de outros alimentos. O uso da nisina ainda é bem restrito e liberado em poucos alimentos, sua molécula é $\mathrm{C}_{143} \mathrm{H}_{230} \mathrm{~N}_{42} \mathrm{O}_{34} \mathrm{~S}_{7}$ (ADITIVOS \& INGREDIENTES, 2015).

A nisina possui um limite para cada produto feito alguns exemplos são o creme Coalhado até $12,5 \mathrm{mg} / \mathrm{kg}$ em pudim de semolina e até mesmo em tapiocas é de $3 \mathrm{mg} / \mathrm{kg}$ e em queijo tipo mascarpone é de $\mathrm{romg} / \mathrm{kg}$. A nisina é um conservante mais natural, porém podemos ter sua adição em alguns produtos específicos de forma restrita pois em grão negativos abaixo de $20^{\circ} \mathrm{C}$ e com $\mathrm{pH}$ por volta de 4 , suas enzimas são retidas pela gordura e composto dos alimentos (ADITIVOS \& INGREDIENTES, 2015).

A natamicina tem seu limite permitido até $5 \mathrm{mg} / \mathrm{kg}$, muito pouco usada em comparação a nisina, é utilizada mais nas partes não consumidas de queijos como casca de cera, temos outros ácidos que são utilizados junto a ela, porém não utilizados como 
flavorizantes (que iria trazer o sabor mais característico do alimento), sua fórmula molecular é $\mathrm{C}_{33} \mathrm{H}_{47} \mathrm{NO}_{13}$ (ADITIVOS \& INGREDIENTES, 2015).

\section{MALEFICIOS CAUSADOS PELOS CONSERVANTES A SAUDE}

Este meio de conservação através de aditivos químicos, quando consumido à longo prazo ou é ingerido uma dose superior ao que é determinado pelos órgãos controladores, pode proporcionar alguns problemas de saúde ao ser humano. Cada conservante, quando ultrapassada a ingestão definida, provoca uma disfunção diferente ao corpo, portanto deve-se estar sempre atento aos sinais de que nosso organismo nos demonstra.

\section{I. ÁCIDO SÓRBICO E SEUS SAIS}

Segundo a Food and Drug Administration (2019), o ácido sórbico e seus derivados são considerados geralmente como seguros, quando usados respeitando as boas práticas de fabricação e os limites definidos pelos órgãos controladores (ANVISA). São conservantes cada vez mais utilizados em substituições de conservantes mais tóxicos, tendo seu uso autorizado em todo o mundo (COELHO, 2008).

Porém, este conservante e seus sais de potássio e sódio, apesar de serem frequentemente utilizados, alguns estudos em animais evidenciam que quando aplicado em quantidade elevada para o consumo, podem gerar toxicidade materna e fetal. Além deste, são constatados outros efeitos adversos como diminuição no peso corporal, diminuição da distância anogenital em filhotes e prejuízos no desenvolvimento físico e funcional (EFSA, 2015 apud ASSIS et al., 2020).

Deve-se também, nos casos de desrespeito aos limites estabelecidos de aplicação, manter uma preocupação em relação à algum desenvolvimento de câncer gastrointestinal, devido à um alto consumo, visto que é a principal via metabólica utilizada por esses aditivos químicos (ASSIS et al., 2020). 


\subsection{NITRITOS E NITRATOS}

Estes aditivos são sais de cura usados em larga escala na indústria alimentícia, principalmente no ramo de carnes e embutidos. Conhecido como uma substância conservadora que protege a deterioração do alimento, este conservante mantém as características sensoriais agindo como fixador de cor, desenvolvendo o sabor e aroma típico dos produtos curados (PARDI, 1996).

No entanto, o uso de nitritos e nitratos gera uma certa discussão devido aos efeitos adversos quando utilizados a um longo prazo. O motivo de maior preocupação é devido aos efeitos tóxicos em consequência de excesso na dieta e pela formação de nitrosaminas (Figura I), sendo como principal a $\mathrm{N}$-nitrosodimetilamina (Figura 2), apresentando efeitos carcinógenos, teratogênicos e mutagênicos (MARTINS; MÍDIO, 2000 apud IAMARINO et al, 2015). $\Omega$

Figura I Modelo molecular de nitrosaminas

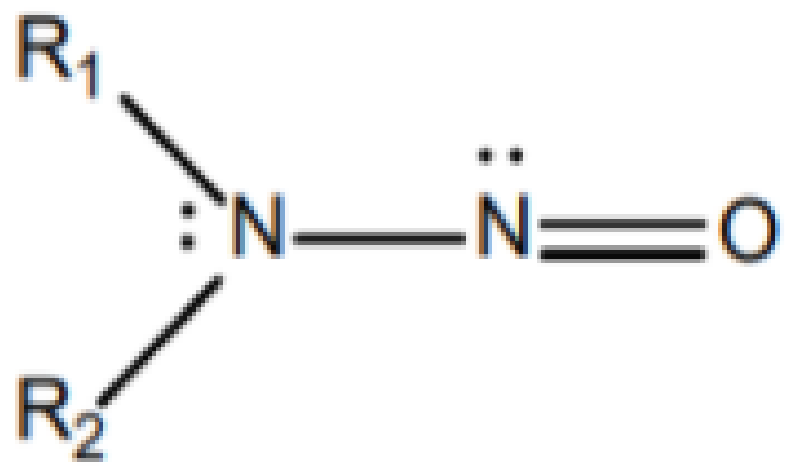

Fonte: Food and Drug Administration, 202I

O nitrito, com uma toxicidade maior que o nitrato, possui como principais sintomas: a formação de metahemoglobina que ocorre quando a hemoglobina é oxidada em uma maior velocidade que a capacidade enzimática normal; vasodilatação e relaxamento da musculatura lisa (IAMARINO, 2015).

Independentemente da quantidade que é aplicada nos alimentos, os nitratos e nitritos possuem uma tendência na formação das nitrosaminas, caracterizando a sua toxicidade. É definida como dose letal para adultos a quantidade de I,o gramas, e em doses 
inferiores observa-se como principais sintomas cefaleia, enrubescimento da face e extremidade e desconforto gastrointestinal (IAMARINO, 2015).

Figura 2 Estrutura molecular da $\mathrm{N}$-nitrosodimetilamina

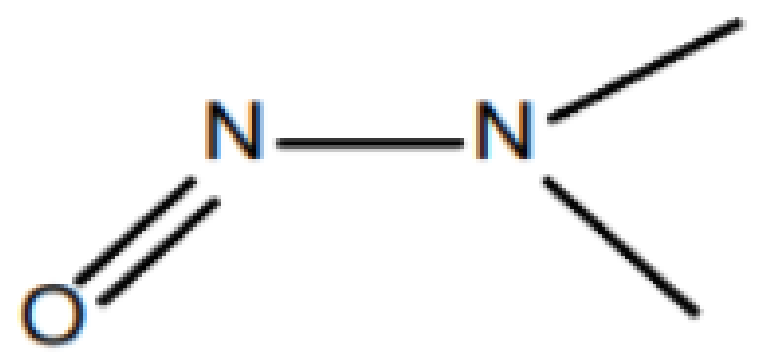

Fonte: Food and Drug Administration, 202I

Além disso, deve-se considerar que a toxicidade desses conservantes pode variar também de acordo com alguns fatores, como: exposição ambiental, idade, estado de saúde, grau de nutrição, estilo de vida e frequência em que é ingerido este aditivo (IAMARINO, 2015).

\section{3. ÁCIDO BENZÓICO E SEUS SAIS}

O ácido benzóico e seus derivados apresentam uma toxicidade bem maior que a dos outros conservantes, possuindo um sabor repulsivo e desagradável. Também é avaliado como um contaminante de risco para o meio ambiente já que é uma substância derivada da indústria química e farmacêutica (JAY, 2005 apud COELHO, 2008).

Segundo a Organização Mundial de Saúde, é aceitável a ingestão de até $5 \mathrm{mg}$ de benzoato por $\mathrm{Kg}$ de peso corporal/dia, porém os limites de aplicação permitido no Brasil varia de acordo com o alimento.

Este conservante possui uma pequena irritação para a pele e grande irritação para os olhos. Há alguns relatos de reações adversas como erupções cutâneas, distúrbios neurológicos, hiperatividade, asma, choque anafilático, rinite e inflamação das membranas mucosas do nariz em casos de atribuição por via oral, inalação ou sobre a pele. É descrito também, casos de crise alérgica em crianças com sensibilidade à aspirina (OLIVEIRA; REIS, 2017). 
Existe um grupo de pessoas que possui um maior risco quando exposto ao ácido benzóico. Quando há sinais de doença hepática como cirrose e hepatite, podem apresentar problemas gastrointestinais, visto que o ácido benzóico causa um aumento da carga de trabalho do fígado principalmente quando administrado junto a um aminoácido L-glicina, sendo encontrado em alimentos ricos em proteína, suplementos dietéticos e anti-ácidos (OLIVEIRA; REIS, 2017).

\section{4. ÁCIDO PROPIÔNICO E SEUS SAIS}

Em estudos subcrônicos utilizando propionato de cálcio e propionato de sódio foram obtidas reações adversas nos animais testados, quando havia exposição a doses elevadas, sendo essas lesões no estômago, redução do consumo de alimentos e diminuição no crescimento. Porém em humanos adultos não houve nenhuma alteração além de uma sutil alcalinidade na urina com o uso de propionato de sódio. É válido ressaltar que o uso do propionato de sódio acarreta a elevação do consumo de sódio, que em grandes quantidades causa prejuízos a saúde. No caso do propionato de cálcio há possibilidade de não causar toxicidade grave, mas existem relatos de efeitos na saúde a longo prazo (PHECHKRAJANG, 2016; HONORATO et al, 2013 apud MENANA, 2017).

Em um estudo realizado sobre alimentação crônica, utilizando ácido propiônico em ratos percebeu-se que o consumo de altas doses causa hiperatividade, irritabilidade, hiperplasia, úlceras e diferentes danos no estômago. No cérebro o ácido propiônico consegue atravessar as membranas e ficar acumulado nas células, o que induz a acidificação intracelular, alterando as liberações dos neurotransmissores, a comunicação e o comportamento neuronal, lembrando a alguns aspectos do autismo (AL- SALEM et al, 2016 apud MENANA, 2017).

Um estudo realizado em células de Allium cepa mostrou que os sais do ácido propiônico podem causar inibição da síntese de DNA em decorrência da diminuição da atividade mitótica, o que induz uma serie de anormalidades mitóticas nas raízes da $\mathrm{A}$. cepa. O uso destes aditivos provoca pontes de anáfase, micronúcleos, células binucleadas e viscosidade, significando que os propionatos induzem quebras cromossômicas, gerando um retardamento cromossômico (TÜRKOGLU, 2008 apud MENANA, 2017). 
No entanto, o ácido propiônico é um composto normal no metabolismo humano, sendo utilizado pela maior parte dos órgãos e tecidos. É utilizado em diversos produtos alimentícios sem nenhuma consequência, visto que as doses utilizadas são baixas, portanto, os riscos a exposição ao ácido propiônico é pequeno (US EPA, I991 apud MENANA, 2017).

\subsection{DIÓXIDO DE ENXOFRE E DERIVADOS}

$\mathrm{Na}$ maior parte da população, o uso do dióxido de enxofre dentro das quantidades estabelecidas não provoca efeitos adversos; porém em certos grupos, principalmente entre os asmáticos, podem ter grande sensibilidade ao seu uso (ENVIRONMENTAL HEALTH SERVICE, 1996; TAYLOR, 1993; LECOS, 1988; TAYLOR; BUSH, 1987; BEHRE, I986; TAYLOR; BUSH,1986 apud POPOLIM, 2004).

Apesar de seu uso em diversos produtos alimentícios, o dióxido de enxofre pode acarretar problemas como a diminuição da biodisponibilidade de vitaminas como a tiamina (BI), ácido fólico ( $\left.\mathrm{B}_{9}\right)$, piridoxina e nicotinamida. Além do diagnóstico de distúrbios neurológicos em uma parcela da população, em que a atividade da enzima sulfito oxidase é reduzida (COELHO, 2008; WONG, 1989 apud FAVERO et al., 2011).

Pessoas sensíveis ao dióxido de enxofre normalmente apresentam sensação de desconforto crescente na garganta, congestionamento no peito, tosse, e raras vezes apresentam dores respiratórias, broncoespasmos, perda de consciência, hipotensão, angioedema, anafilaxia em asmáticos e dermatite de contato. Também foram registrados problemas gastrointestinais como dores abdominais, náuseas, diarreia e vômitos. A proporção da reação tem relação com o tipo de alimento, acidez, quantidade de dióxido de enxofre e da sensibilidade do indivíduo (LECLERCQ et al, 200o; SIMON, 20oo; PIZZOFERRATO; DI LULLO; QUATTRUCCI, 1998; TAYLOR, 1993; SAFAVI; ENSAFI, I99I; BRANEN; DAVIDSON; SALMINEN, 1990; TAYLOR; BUSH, I987; BEHRE, I986; TAYLOR; BUSH， 1986; SULLIVAN; SMITH， 1985; WALKER， 1985; QUATTRUCCI, I98I apud POPOLIM, 2004).

Em humanos os sulfitos podem ocasionar anafilaxia, urticaria, angioedema, hipotensão, náusea, irritação gástrica local, dores de cabeça, distúrbios de comportamento, 
erupções cutâneas, diarreia e crise asmática em asmáticos com sensibilidade a sulfitos (MACHADO; TOLEDO, 2006; LÜCK; JAGER, I995; SAMPICCHIO et al, 2008; PEREIRA et al, 2008; VALLY; THOMPSPON, 20or apud FAVERO et al, 201I).

Para a maior parcela da população não existem provas de que sulfitos provocam riscos à saúde, principalmente devido aos limites de utilização atuais. Chegou-se a essa conclusão a partir de comparações feitas a estimativa de ingestão de sulfitos com informações de sua toxicidade e experimentos realizados em animais (RIBERA et al, 200I; TIL; FERON, 1992; HUI et al, 1989; TAYLOR; BUSH, 1987; TAYLOR; BUSH, 1986; DULAK; CHIANG; GUNNISON, 1984; GUNNISON et al, 1981; GIBSON; STRONG, 1974; GIBSON; STRONG, I973; SHTENBERG; IGNAT’VE, i970 apud POPOLIM, 2004).

Alguns estudos expressavam que os sulfitos acarretavam episódios de asma em pessoas asmáticas, podendo ocorrer, raras vezes, reações asmáticas graves ou anafiláticas. Por isso, a FDA solicitou a Federation of American Societies for Experimental Biology (FASEB), que organizasse um painel revisional para que fosse reavaliada a segurança dos sulfitos. A conclusão final foi que os sulfitos não são teratogênicos, mutagênicos ou carcinogênicos nos animais utilizados nos testes (RENWICK, I995; SAPPERS, 1993 apud POPOLIM, 2009).

No ano de 1988 o FDA implantou regras novas para o uso dos sulfitos nos alimentos, obrigando a informação de sua presença nos rótulos dos alimentos quando seu limite detectável fosse superior a io $\mathrm{ppm}$. Em restaurantes e supermercados, alguns alimentos necessitavam de placas ou outras formas de indicar a presença do composto nos alimentos (SAPPERS, 1993 apud POPOLIM, 2009).

Diversas reclamações foram feitas ao FDA desde novembro de 1982 relacionadas aos sulfitos. Por isso, em 1985 foi criado o sistema chamado de Adverse Reaction Monitoring System, com a finalidade de fiscalizar tais reclamações. Em 1987 foi determinado que $51 \%$ das reclamações recebidas entre os anos de 1982 e 1985 poderiam ser classificadas como decorrentes de reações serias, contendo 17 mortes que foram relacionadas ao uso dos sulfitos em alimentos e medicamentos (LECOS, 1988 apud POPOLIM, 2004). 


\section{6. ÁCIDO LÁCTICO E SEUS DERIVADOS}

Em razão de sua leve acidez, presença do grupo carboxílico e hidroxílico, que permitem diversas transformações químicas, estabilidade térmica e química, também é considerado pela Food and Drugs Administration (FDA) um composto não tóxico utilizando doses consideráveis.

Esse tipo de ácido é produzido nas bactérias conhecidas como bactérias ácidoláticas, que apresentam benefícios à saúde daqueles que as ingerem. Tais bactérias são capazes de sintetizar substâncias microbianas que agem contra as bactérias patogênicas, competir pelos nutrientes necessários para o crescimento de microrganismos patogênicos e inativar toxinas e seus receptores (MATSUMOTO et al, 2005; PANT et al, 2007 apud LIMA; TAUBE, 2015).

Estudos sobre a fisiologia, bioquímica, genética e biologia molecular das bactérias ácido-lácticas conseguiram detectar compostos capazes de levar ao fenômeno conhecido

como antibiose, um desses compostos é chamado de bacteriocina, que destroem a integridade da membrana citoplasmática através da formação de poros, gerando a perda de pequenos compostos e íons (DAVIDSON; HOOVER, 1993 apud LIMA; TAUBE, 2015).

As bacteriocinas possuem uma natureza química que permite facilmente sua degradação no trato intestinal dos seres humanos e dos animais, fazendo com que sua toxicidade seja perdida (PIARD et al, 1992 apud LIMA; TAUBE, 2015). Estudos realizados com diversas bacteriocinas demonstraram que esse tipo de composto é atóxico e não provoca reações imunológicas adversas (MARUGG, I99I apud LIMA; TAUBE, 2015).

\section{7. ÁCIDO ACÉTICO E ACETATOS}

Em altas concentrações pode causar danos prejudiciais à saúde, pois é um reagente perigoso em risco de vida (classe - 2). Em seu manuseio deve ter muito cuidado pois pode ocasionar lesões na pele e se ficar por muito tempo pode causar queimaduras de $2^{\circ}$ grau, corrosões severas, irritações, e caso ingerido ocorrem vômitos com sangue, corrosões na 
boca, diarreia, uremia, colapso circulatório, choque, hemólise e em contato com os olhos pode causar cegueira (TEVES, 20or).

O ácido acético é um composto monocarboxílico que apresenta em sua característica um gosto ruim e um odor notável e desagradável. Por ser muito utilizado deve haver muito cuidado, pois em alta quantidade pode causar intoxicação aguda, com isso as doses em alimentos são sempre baixas. Muitos conhecem esse ácido no vinagre, porém está presente em outros alimentos, como conservante para conter os microrganismos e bactérias (RODRIGUES et al, 2013).

\section{8. ÁCIDO P-HIDROXIBENZÓICO E SEUS ÉSTERES (PARABENOS)}

O ácido p-hidroxibenzóico está sendo substituído ou utilizados com mais cuidado na indústria de cosmético, pelo seu alto índice de alergias e ferimentos como urticarias, broncoespasmos, entre outras complicações (QUERINO; SILVA, 2018).

O P-hidroxibenzóico (parabeno), é de toxicidade aguda baixa e se utilizado indevidamente ou em quantidade maior estabelecida pode causar problemas como tosse, vômitos e irritações. Tendo em vista que pode ser usado para vários produtos como conservante com um nível máximo determinado (RODRIGUES et al, 2013).

Durante muito tempo os parabenos foram classificados como uma categoria de substâncias seguras para a utilização, porém atuais estudos mostram que os parabenos possuem potenciais efeitos no sistema endócrino, efeito estrogênico e potencial carcinogênico. A partir de tais descobertas cresceu o interesse das agências reguladoras a nível internacional, por isso o propilparabeno na utilização como conservante alimentar, permitindo apenas o uso do metilparabeno e etilparabeno, tendo restrições em relação a outros conservantes.

\subsection{NISINA E NATAMICINA}

A natamicina é um composto muito utilizado na indústria farmacêutica em tratamento oftalmológico; já na indústria de alimentos seu uso não é tão usado. A ingestão 
desse conservante em excesso pode trazer malefícios à saúde como náuseas, vômitos e diarreias (LAURINDO, 2017).

Quando usado como conservante alimentar em altas concentrações e gera danos ao consumidor, realiza-se uma investigação para obtenção de dados mais consistentes. Segundo a Agência Nacional de Vigilância Sanitária é permitido fazer o uso deste aditivo desde que não haja a ultrapassagem do limite pré-estabelecido (LAURINDO, 2017).

A nisina não é eficiente contra bolores, leveduras e vírus. Alguns produtos foram testados para a identificação da concentração, os quais alguns estavam acima do permitido, porém mesmo sendo alto não chega a ser tóxico. Muitos produtos que contêm este aditivo não possuem a informação no rótulo, assim o consumidor não tem ciência do que ele está comprando e ingerindo (MOLOGNONI, 2015)

\section{CONCLUSÃO}

É possível concluir a partir do presente trabalho que os aditivos químicos como conservantes alimentares, tem benefícios e malefícios como todos os outros meios de conservação.

Para gerar menos problemas é necessário seguir as regulamentações, assim como as boas práticas de fabricação. É sempre necessário utilizá-los nas concentrações corretas visando a conservação adequada do alimento e, também, a prevenção de danos à saúde de seus consumidores.

Muitos conservantes podem ser encontrados naturalmente no corpo humano, como é o caso do ácido láctico, que é um dos que trazem menores riscos à saúde. No intuito de também diminuir os malefícios alguns conservantes estão sendo substituídos por outros que sejam menos agressivos a saúde, como por exemplo os nitritos e nitratos que estão sendo trocados por sorbato de potássio no objetivo de inibir a bactéria do botulismo.

Apesar dos conservantes já terem trazido malefícios a uma parte da população, é possível afirmar que ao administrá-los da maneira correta, as chances de trazer reações adversas a saúde diminui consideravelmente. Essa classe de substâncias é capaz de conservar o alimento sem prejudicar a qualidade do alimento, eliminando micro- 
organismos prejudiciais à saúde e aumentar o prazo de validade, a aparência e outras características.

\section{REFERÊNCIAS}

\section{ADITIVOS E INGREDIENTES. Os Conservantes mais Utilizados nos Alimentos. Edição 123, 2015. Disponível em:} https://aditivosingredientes.com.br/upload_arquivos/2016or/2016010485708001453470366.p df >. Acesso em: 26/03/202I

ADITIVOS E INGREDIENTES. Ação dos Conservantes nos Alimentos. 2013.
Disponível https://aditivosingredientes.com.br/upload_arquivos/201605/2016050542177001463864883.p df >. Acesso em: 07/o7/2021

ADITIVOS E INGREDIENTES. Os Sorbatos na Conservação de Alimentos. Edição ir8, 2015. Disponível em: < https://aditivosingredientes.com.br/upload_arquivos/2016or/2016010628577001453487283.pd f >. Acesso em: 13/o7/2021

ADITIVOS E INGREDIENTES. Conservação de Alimentos por Aditivos Químicos. Edição 63, 2009. Disponível em: http://insumos.com.br/aditivos_e_ingredientes/materias/I25.pdf >. Acesso em: 07/o7/202I

ANVISA. Portaria no 540, de 27 de outubro de 1997. Disponível em: < https://www.gov.br/agricultura/pt-br/assuntos/inspecao/produtos-vegetal/legislacaoI/biblioteca-de-normas-vinhos-e-bebidas/portaria-no-540-de-27-de-outubro-de1997.pdf/view >. Acesso em: 23/06/2021

ANVISA, Gerência de Ações de Ciência e Tecnologia de Alimentos, guia de procedimentos para pedidos de inclusão e extensão de uso de aditivos alimentares e coadjuvantes de tecnologia de fabricação na legislação brasileira, 2009. Disponível em: < http://portal.anvisa.gov.br/documents/33916/389979/Guia+de+Procedimentos+para+Pedi dos + de + Inclu s\% $\mathrm{C}_{3} \% \mathrm{~A}_{30}+\mathrm{e}+$ Extens $\% \mathrm{C}_{3} \% \mathrm{~A}_{30}+\mathrm{de}+\mathrm{Uso}_{\mathrm{de}}+$ Aditivos + Alimentares $+\mathrm{e}+\mathrm{Coa}$ djuvantes+de+Tecnologia + de + Fabrica $\% \mathrm{C}_{3} \% \mathrm{~A}_{7} \% \mathrm{C}_{3} \% \mathrm{~A}_{30}+$ na + Legisla $\% \mathrm{C}_{3} \% \mathrm{~A}_{7} \% \mathrm{C}_{3} \% \mathrm{~A}_{30}$ + Brasileira.pdf/ad2fia36-276c-4115-ba6b-62ccf330540o >. Acesso em: 24/o6/2021

ARIAS, J. L. O. Determinação de Conservantes em Alimentos Processados Empregando Quechers, Sillme e HPLC-UV: Estudo de Métodos e Estimativa da Ingestão Diária. Rio Grande do Sul, 2019.

ASSIS, R. C. et al. Ácido Sórbico e Câncer Gastrointestinal: uma Revisão Integrativa. Ensaios e Ciência, 2020.

ATKINS, P. W. Inorganic Chemistry. Ed. 3, 1999.

AUN, M. V. et al. Aditivos em alimentos. Revista Brasileira de Alergia e Imunopatologia, v. 34, n. 5, p. 177-185, 2011. 
AZEREDO, H.M.C. Fundamentos de estabilidade de alimentos. Brasília: Embrapa, 2012.

BRASIL. Resolução no 04/88, de 24 de Novembro de 1988, ABIA - Compêndio da Legislação de Alimentos - Atos do Ministério da Saúde. Diário Oficial da República Federativa do Brasil, 1988.

BRASIL. Ministério da Saúde, ANVISA. Portaria $\mathrm{n}^{\circ}$ 1004, de in de dezembro de 1998, republicada no diário oficial da união de 22 de março de 1999. Regulamento Técnico: "Atribuição de Funções de Aditivos, Aditivos e seus Limites Máximos de uso para a Categoria 8 - Carne e Produtos Cárneos". Diário Oficial da União, Brasília, DF, 22 de março de 1999 .

CAPELLARI, J. B. Biossíntese de Ácido Láctico por Lactobacillus Amylovorus a Partir de Resíduos Agroindustriais. Joinville, 2010.

CÉ, N. Utilização de Filmes de Quitosana Contendo Nisina e Natamicina para Cobertura de Kiwis e Morangos Minimamente Processados. Porto Alegre, 2009.

COELHO, S. F. L. Efeito de Diferentes Concentrações de Conservantes Alimentícios no Crescimento In Vitro de Fungos Termorresistentes e Bactérias Patogênicas. Maceió, 2008.

COPETTI, N. F. Aditivos Alimentares e Suas Consequências para a Saúde Humana, 2019 .

COSTA, J. C. D. Validação de um Método de Cromatografia de Alta Eficiência para Determinação de Conservantes em Gêneros Alimentícios. Lisboa, 2015.

DAVIDSON, P. M., SOFOS, J. N., BRANEN, A. L. Antimicrobials in Food. 3. Ed. CRC Press, 2005. Disponível em: < http://base.dnsgb.com.ua/files/book/Agriculture/Foods/Antimicrobials-in-Food.pdf >. Acesso em: 18/06/2021

DIONYSIO, R. B.; MEIRELLES, F. V. P. Conservação de alimentos, 2009.

FAVERO, D. M.; RIBEIRO, C. S. G.; AQUINO, A. D. Sulfitos: Importância na Indústria Alimentícia e seus Possíveis Malefícios à População. Curitiba, 20II.

FDA - Food and Drug Administration. Code of Federal Regulations, 2I CFR I82. Title 2IFood and Drugs, vol. 3. Cap. I - Food and Drug Administration, Department of Health and Human Services. Part 182 - Substances Generally Recognized as safe. Subpart DChemical Preservatives, §i82.3640 Potassium sorbate. 2019. Disponível em: < http:// wwwr.inca.gov.br/estimativa/2018/estimativa-2018.pdf >. Acesso: 27/o8/2021

FIORUCCI, A. R.; SOARES, M. H. F.; CAVAlHEIRO, E. T. G. Ácidos Orgânicos: Dos Primórdios da Química Experimental à sua Presença em Nosso Cotidiano. 2002

FOOD INGREDIENTS BRASIL. Conservantes. Edição I8, 20II. Disponível em: < https://revista-fi.com.br/upload_arquivos/201606/2016060507789001467204027.pdf >. Acesso em: 03/05/2021 
FOOD INGREDIENTS BRASIL. Conservação de Alimentos por Aditivos Químicos. Edição 22, 2012. Disponível em: < https://revistafi.com/upload_arquivos/201606/2016060331891001467132636.pdf >. Acesso em: 10/o7/2021

GArCíA, C. A.; ARrÁzolA, G. S.; DURANGO, A. M. Produccíon de Ácido Láctico por Vía Biotecnológica. Colômbia, 2010.

IAMARINO, L. Z. et al. Nitritos e Nitratos em Produtos Cárneos Enlatados e/ou Embutidos. 2015.

LAURINDO, J. Teor de Natamicina, Caracterização Físico- Química, Perfil de Ácidos Graxos e Índices de Qualidade Lipídica em Queijo Azul e Tipo Gorgonzola. Londrina, 2017.

LIMA, A.; TAUBE, J. P. Bactérias Lácticas e sua Importância na Indústria de Alimentos e Saúde: Uma Revisão. Pará, 2015.

MACHADO, R. M. D. et al. Presença dos Ácidos Benzóicos e Sórbico em Vinhos e Sidras Produzidos no Brasil. Ciênc. Tecnol. Aliment., Campinas, 2007.

MENANA, M. F. F. F. Implementação e Validação do Método de Quantificação de Ácido Propiónico por HPLC em Produtos de Padaria e Pastelaria. Lisboa, 2017.

MODANEZ, L. Aceitação de Alimentos Irradiados: Uma Questão de Educação. São Paulo, 2012.

MOLOGNONI, L. Desenvolvimento de Metodologias para Análise Simultânea de Ácido Sórbico, Natamicina, Nisina e Tilosina em Produtos Lácteos por Cromatografia Líquida Acoplada à Espectrometria de Massas. Florianópolis, 2015.

MOURA, S. I. B. Aplicação de Conservantes Alimentares para Controle da Contaminação por Listeria spp. e Bolores em Queijos. Covilhã, 2011.

OLIVEIRA, P. H. R.; REIS, R. R. Ácido Benzóico. Revista Virtual de Química, 2017.

PÉREZ, L. S. et al. Efecto del Ácido Benzóico em la Capacidad Antioxidante de Germinados de Trigo. Revista Mexicana de Ciêcias Agrícolas, 2016.

POPOLIM, W. D. Estimativa da Ingestão de Sulfitos por Escolares pela Análise Qualitativa da Dieta. São Paulo, 2004.

POPOLIM, W. D. Análise de Sulfitos em Sucos de Frutas e Estimativa de seu Consumo por Escolares. São Paulo, 2009.

QUERINO, E. T. S.; SILVA, R. P. Análise dos Riscos à Saúde, dos Parabenos em Cosméticos. Rio Grande do Norte, 2018.

RAHMAN, M. S. Handbook of Food Preservation. 2. Ed. CRC Press, 2007. Disponível em:

http://www.cold.org.gr/library/downloads/Docs/Handbook\%20of\%2oFood\%2oPreservat ion.PDF >. Acesso em: 17/05/2021 
RASHID, R. Optimization and Modeling of Lactic Acid Production from Pineapple Waste. Malaysia, 2008.

RODRIGUES, A. F. S. et al. Aditivos Alimentares: Conceitos, Aplicações e Toxicidade. Minas Gerais: FUCAMP, 2013.

TEVES, M. L. U. Ácido Acético. São Paulo, 2003.

URBEN, A. F. et al. Produção de Cogumelos por Meio de Tecnologia Chinesa Modificada. 3. Ed. Brasília: Embrapa, 2017.

ZEHETMEYER, G. Desenvolvimento e Caracterização de Embalagens Ativas Compostas de PBAT com Incorporação de Nisina. Porto Alegre, 2016.

ZUIM, D. R. Estudo da Adsorção de Componentes do Aroma de Café (Benzaldeído e Ácido Acético) Perdidos Durante o Processo de Produção de Café Solúvel. Curitiba, 2010. 